\title{
A 59-year-old Female Post Bariatric Surgery with Severe Vitamin D Deficiency and Severe Hypocalcemia Induced by Denosumab Injection for Osteoporosis
}

\author{
John Beal $^{1 *}$, Soemiwati W Holland ${ }^{2}$, Krishna Chalasani ${ }^{2}$ and Mohammad A Hossain ${ }^{1}$ \\ ${ }^{1}$ Department of Medicine, Jersey Shore University Medical Center, Neptune NJ, USA \\ ${ }^{2}$ Department of Endocrinology and Metabolism, Jersey Shore University Medical Center, Hackensack Meridian Health, Neptune NJ, USA
}

\begin{abstract}
Denosumab is a human monoclonal antibody that binds to receptor activator of nuclear factor kappa-B ligand (RANKL) and blocks the interaction between RANKL and RANK on the surface of osteoclasts, thereby preventing osteoclast formation resulting in decreased bone resorption and increased bone mass in osteoporosis. A rare yet serious side effect of this treatment option is severe hypocalcemia, and thus current guidelines recommend concurrent calcium and vitamin D supplementation. Here, we report a case of a 59-year-old female with history of gastric bypass, primary hyperparathyroidism, and osteoporosis presents two weeks after initiating denosumab therapy with symptoms of severe hypocalcemia. Serum calcium and vitamin D levels revealed severe acute deficiencies that responded to continuous intravenous replacement followed by high dose oral supplementation over a nineteen-day hospitalization. There are currently no reported cases of acute denosumab-induced hypovitaminosis D. Our case may represent a previously undocumented adverse effect of denosumab that clinicians should be aware of when treating severe drug-induced hypocalcemia.
\end{abstract}

\section{Introduction}

Denosumab is a human monoclonal antibody that binds receptor activator of nuclear factor kappa-B ligand (RANKL) and inhibits interaction between RANKL and RANK on the surface of osteoclasts, which prevents osteoclast formation and causes decreased bone resorption and increased bone mass [1]. Osteoporosis is characterized by low bone mass, microarchitectural disruption, and increased skeletal fragility. It is common in those who have undergone Rouxen-Y gastric bypass surgery, which causes reduced gastric acid levels necessary for adequate calcium absorption and decreased vitamin D due to relative bypass of its primary absorption points in the duodenum and proximal jejunum [2,3]. Denosumab is a reasonable option for osteoporosis treatment in patients with gastric bypass surgery due to intestinal malabsorption and risk of anastomotic ulceration with oral bisphosphonates [4]. A rare yet potentially fatal adverse effect of denosumab is severe hypocalcemia and Vitamin D deficiency, which is often prolonged secondary to its long half-life and therefore difficult to treat in many cases [5]. We present a case of denosumab-induced severe hypocalcemia in a patient with history of gastric bypass who also was found to have acute severe hypovitaminosis $\mathrm{D}$ despite post-treatment vitamin $\mathrm{D}$ supplementation. Thus we hypothesize a potentially causal relationship between denosumab and acute severe vitamin $\mathrm{D}$ deficiency in high-risk patients, specifically with intestinal malabsorption and resultant predisposition to becoming vitamin $\mathrm{D}$ deficient.

\section{Case Presentation}

A 59 year old Caucasian female with history of Roux-en-Y gastric bypass presented to the emergency department with progressive numbness of her face, arms, and legs over a two week period. Her symptoms also included fine hand tremors bilaterally and increased limb pain of the bilateral thighs. No seizure-like activity, confusion, or abdominal pain were reported. Approximately two months prior to presentation, the patient was found to have hypercalcemia due to primary hyperparathyroidism. She underwent a bone densitometry scan as part of her outpatient workup, which revealed osteoporosis of the left arm. Two weeks prior to admission she received a single dose of denosumab $60 \mathrm{mg}$ subcutaneously, after which she experienced generalized urticaria, shortness of breath, and limb pain of the bilateral lower extremities. Her rash and dyspnea resolved with supportive care, however her bilateral limb pain persisted in addition to her presenting symptoms mentioned above. Vital signs on admission: blood pressure $104 / 57 \mathrm{mmHg}$, pulse 78 , respiratory rate 18 , and temperature 97.6. Physical exam elucidated a positive Chvostek sign and diminished sensation of the bilateral face, arms, and legs. Motor strength was $4 / 5$ in the bilateral lower extremities and $4 / 5$ in the bilateral upper extremities. Mild tremors were also noted in bilateral upper extremities. Otherwise heart, lung, abdominal, and neck exam were within normal limits. Comprehensive metabolic panel on admission as seen in Table 1 included normal electrolytes, mildly elevated creatinine, and low calcium $5.4 \mathrm{mg} / \mathrm{dL}(10.4 \mathrm{mg} / \mathrm{dL}$ prior to denosumab) with normal albumin. Other significant laboratory values included parathyroid hormone $985.4 \mathrm{pg} / \mathrm{ml}, 25$-hydroxyvitamin D less than $7.0 \mathrm{ng} / \mathrm{ml}(19.6 \mathrm{ng} / \mathrm{ml}$ prior to denosumab), and phosphorus 2.0 $\mathrm{mg} / \mathrm{dL}$. Electrocardiogram showed prolonged QTc interval.

${ }^{\star}$ Correspondence to: John Beal MD, Internal Medicine Residency Program, Department of Medicine, Jersey Shore University Medical Center, 1945 State Route 33, Neptune, NJ 07753, USA, Tel: 732-776-4483; Fax: 732-776-3795; E-mail: John.Beal@hackensackmeridian.org

Key words: denosumab, hypocalcemia, osteoporosis, vitamin d deficiency

Received: June 12, 2018; Accepted: June 20, 2018; Published: June 25, 2018 
Beal J (2018) A 59-year-old Female Post Bariatric Surgery with Severe Vitamin D Deficiency and Severe Hypocalcemia Induced by Denosumab Injection for Osteoporosis

After a total of 8 grams of IV calcium gluconate in divided doses failed to normalize the patient's serum calcium within the first 24 hours, on day 2 of hospitalization she was initiated on calcium gluconate continuous infusion. Oral calcium and vitamin D supplementation were started as well: calcitriol oral solution $0.25 \mathrm{mcg}$ twice daily and calcium carbonate $1000 \mathrm{mg}$ every 6 hours. Calcium gluconate infusion was stopped on day 3 when her serum calcium reached $8.1 \mathrm{mg} / \mathrm{dL}$. Hypocalcemia persisted with difficulty maintaining corrected serum calcium levels $>8 \mathrm{mg} / \mathrm{dL}$ on serial monitoring (Figure 1), and thus oral replacement therapy with calcium and vitamin were increased. The patient also required periodic repletion for hypophosphatemia with sodium phosphate. Calcium carbonate dosing was increased to $5000 \mathrm{mg}$ by mouth every 4 hours. Intravenous calcium gluconate doses of $1-2 \mathrm{~g}$ were required daily in addition to oral therapy during hospitalization to maintain serum calcium greater than $8 \mathrm{mg} / \mathrm{dL}$. Finally after stabilization of her serum calcium and vitamin D levels and resolution of symptoms, the patient was discharged on day 19 with high dose oral calcium $(6000$ mg every 4 hours), vitamin D (ergocalciferol) and calcitriol ( $0.5 \mathrm{mg}$ PO every 6 hours) supplements. She was advised to follow up at outpatient clinic with close clinical and laboratory monitoring.

\section{Discussion}

Severe hypocalcemia is a rare adverse effect of denosumab occurring in less than $0.1 \%$ of post-menopausal females with osteoporosis, according to a 3-year, randomized, double-blind, placebo-controlled, multinational study [6]. Its long half-life (approximately 25-28 days) and prolonged effect makes this deficiency especially difficult to correct [7]. Treatment regimens and length of hospitalization for this condition vary from case to case based on various comorbidities of the patients involved. We present a patient with history of bariatric surgery who was found to have denosumab-induced severe hypocalcemia with concurrent acute severe vitamin D deficiency. Although our patient did exhibit low pre-treatment vitamin D levels, we observed an acute decrease in serum vitamin $\mathrm{D}$ levels shortly following administration of denosumab (Table 2). Treatment guidelines recommend calcium and vitamin D supplementation for patients taking denosumab [1], but vitamin D deficiency in and of itself is not a listed adverse effect.
Our patient's gastric bypass surgery predisposed her to intestinal malabsorption and deficiency of vitamin $\mathrm{D}$, which proved to be a significant obstacle in restoring and maintaining normal serum calcium levels. We hypothesize that denosumab may exacerbate existing vitamin D deficiency in at-risk patient populations.

Few other cases highlighting vitamin D levels in denosumabtreated individuals have been reported in literature $[8,9]$. One patient with osteoporosis and intestinal malabsorption secondary to Crohn's disease who presented with denosumab-induced severe hypocalcemia experienced symptom resolution after a three-day hospitalization. This patient was found to have severe vitamin D deficiency, but pretreatment serum vitamin D levels were not drawn. Treatment included high dose IV calcium gluconate followed by oral calcium and vitamin D supplementation [8]. Another case of denosumab-induced severe hypocalcemia occurred in a patient with history of bariatric surgery

Table 1. Summary of Laboratory Values on Admission

\begin{tabular}{|l|c|c|}
\hline Laboratory data & Value & Reference Range \\
\hline Sodium $(\mathrm{mmol} / \mathrm{L})$ & 139 & $136-145$ \\
\hline Potassium $(\mathrm{mmol} / \mathrm{L})$ & 3.7 & $3.5-5.2$ \\
\hline Chloride $(\mathrm{mmol} / \mathrm{L})$ & 109 & $96-110$ \\
\hline Bicarbonate $(\mathrm{mmol} / \mathrm{L})$ & 20 & $24-31$ \\
\hline Glucose $(\mathrm{mg} / \mathrm{dL})$ & 89 & $70-99$ \\
\hline Blood urea nitrogen $(\mathrm{mg} / \mathrm{dL})$ & 14 & $5-25$ \\
\hline Creatinine $(\mathrm{mg} / \mathrm{dL})$ & 1.17 & $0.44-1.00$ \\
\hline Calcium $(\mathrm{mg} / \mathrm{dL})$ & 5.4 & $8.5-10.5$ \\
\hline Albumin $(\mathrm{g} / \mathrm{dL})$ & 3.6 & $3.5-5.0$ \\
\hline Alkaline phosphatase (iU/L) & 194 & $38-126$ \\
\hline Aspartate aminotransferase $(\mathrm{iU} / \mathrm{L})$ & 16 & $10-42$ \\
\hline Alanine aminotransferase $(\mathrm{iU} / \mathrm{L})$ & $<9$ & $10-60$ \\
\hline Parathyroid Hormone $(\mathrm{pg} / \mathrm{ml})$ & 985.4 & $12-88$ \\
\hline
\end{tabular}

Table 2. Serum 25-Hydroxy Vitamin D Levels Before and After Denosumab Administration

\begin{tabular}{|c|c|}
\hline Time in course of illness & Serum 25-Hydroxy Vitamin D Level (ng/ml) \\
\hline 14 days prior to admission (pre-denosumab) & 19.6 \\
\hline Day 3 (post-denosumab) & $<7.0$ \\
\hline Day 19 (time of discharge) & 21.0 \\
\hline
\end{tabular}

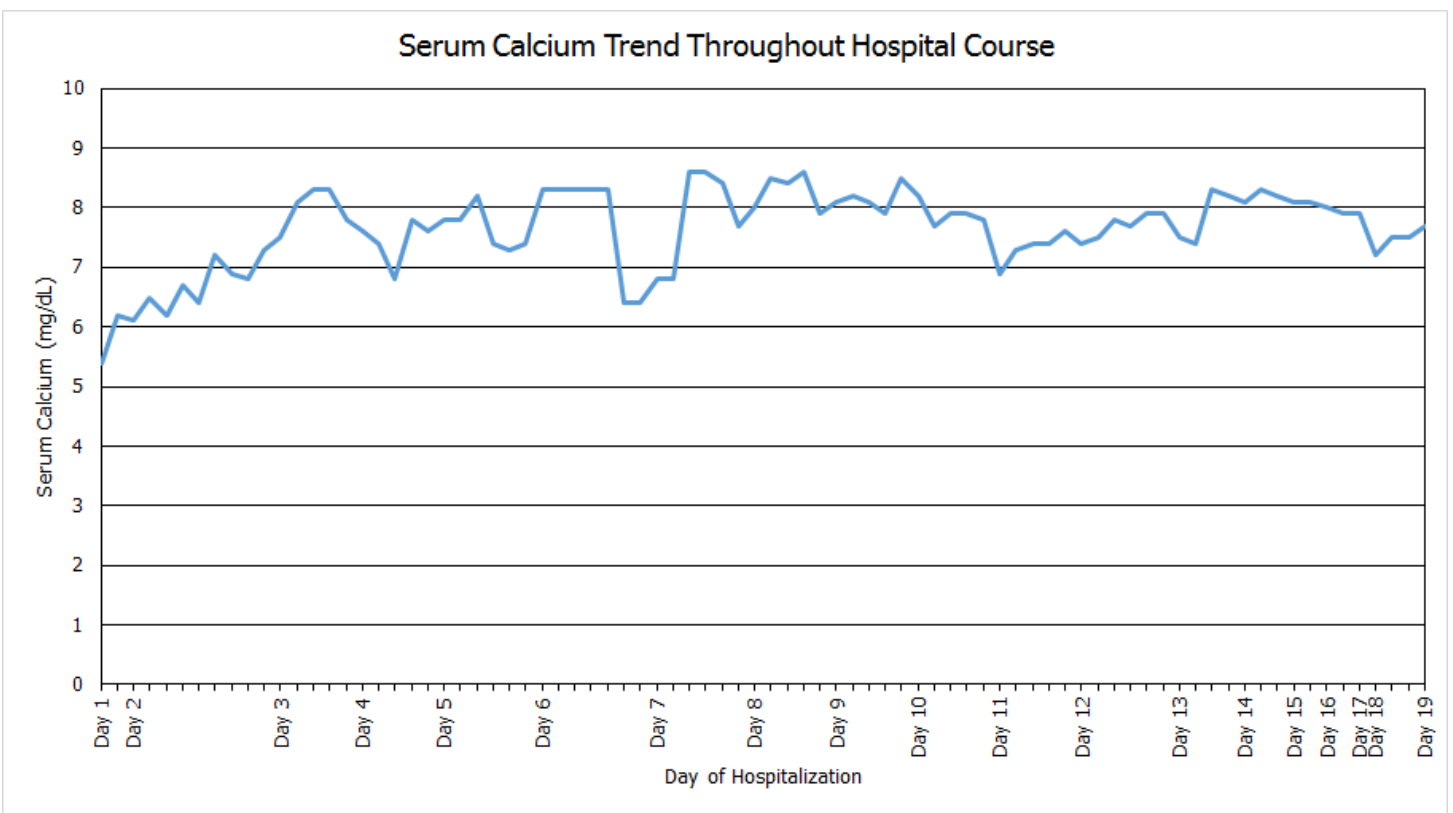

Figure 1. Corrected serum calcium trend from admission to discharge 
with mild vitamin D deficiency, yet vitamin D levels remained unchanged after administration of the RANKL inhibitor. The patient improved with eight weeks of IV calcium followed by oral calcium, phosphorus and vitamin D supplementation [9].

There are limited cases in the literature that report severe hypovitaminosis $\mathrm{D}$ in patients treated with denosumab. Therefore, it is important for clinicians who use this medication to consider vitamin $\mathrm{D}$ deficiency and implement laboratory monitoring before and after denosumab administration. Identifying and closely following this potential side effect guides optimal therapy and may prevent serious complications of drug-induced hypocalcemia.

Statement of Ethics: The authors have no ethical conflicts to disclose

Funding Sources: This project was not supported by any grant or funding agencies

Consent: The patient described in the case report had given informed consent for the case report to be published.

Conflict of Interests: The authors declare that there is no conflict of interests regarding the publication of this paper.

\section{References}

1. Cummings SR, San Martin J, McClung MR, Siris ES, Eastell R, et al. (2009) Denosumab for prevention of fractures in postmenopausal women with osteoporosis. $N$ Engl J Med 361: 756-765. [Crossref]

2. Beckman LM, Earthman CP, Thomas W, Compher CW, Muniz J, et al. (2013) Serum 25(OH) Vitamin D Concentration Changes after Roux-en-Y Gastric Bypass Surgery. Obesity (Silver Spring) 21: E599-E606. [Crossref]

3. Johnson JM, Maher JW, DeMaria EJ, Downs RW, Wolfe LG, et al. (2006) The long-term effects of gastric bypass on vitamin D metabolism. Ann Surg 243: 701-704. [Crossref]

4. Stein EM, Silverberg SJ (2014) Bone Loss After Bariatric Surgery: Causes, Consequences and Management. Lancet Diabetes Endocrinol 2: 165-174. [Crossref]

5. Laskowski LK, Goldfarb DS, Howland MA, Kavcsak K, Lugassy DM, et al. (2016) A RANKL Wrinkle: Denosumab-Induced Hypocalcemia. J Med Toxicol 12: 305-308. [Crossref]

6. Papapoulos S, Lippuner K, Roux C, Lin CJ, Kendler DL, et al. (2015) The effect of 8 or 5 years of denosumab treatment in postmenopausal women with osteoporosis: results from the FREEDOM Extension study. Osteoporos Int 26: 2773-2783. [Crossref]

7. Lewiecki EM (2011) Safety and tolerability of denosumab for the treatment of postmenopausal osteoporosis. Drug Healthc Patient Saf 3: 79-91. [Crossref]

8. Spiegel MC, Tidwell T, Mulyala R, Katta N (2014) Denosumab-Induced Severe Hypocalcemia in a Patient with Crohn's Disease. Journal of Academic Hospital Medicine.

9. Portilla AJ, Soler GS, Planella JRU, Perez MSG, Font MN, et al. (2017) Severe hypocalcemia induced by Denosumab in a patient with Osteroporosis after malabsorptive bariatric surgery. 19th European Congress of Endocrinology. Endocrine Abstracts 49: EP294.

Copyright: (C2018 Beal J. This is an open-access article distributed under the terms of the Creative Commons Attribution License, which permits unrestricted use, distribution, and reproduction in any medium, provided the original author and source are credited. 